\title{
Review on Somatic Hybridization and its Role in Crop Improvement
}

\author{
Temesgen Begna* \\ Chiro National Sorghum Research and Training Center, P.O.BOX 190, Chiro, Ethiopia
}

*Corresponding Authors: Temesgen Begna, Chiro National Sorghum Research and Training Center, P.O.BOX 190, Chiro, Ethiopia

\begin{abstract}
Somatic hybridization is one of the most important uses of protoplast culture. This is particularly significant for hybridization between species or genera, which cannot be made to cross by conventional methods of sexual hybridization. The aim of somatic hybridization is to transfer traits which are desired and generate a beneficial crop plants without genetic engineering and as well as facilitate conventional breeding through providing novel crop lines. Somatic hybridization broadens the base of accessible germplasm and offers additional opportunities for introgression of desirable traits into cultivars. Plant protoplasts can be fused and the fusion products cultured to produce somatic hybrid plants. This technique has been used to produce germplasm previously unavailable to the plant breeder. Several researchers have emphasized production of hybrids between distantly related, sexually incompatible species, but many of these hybrids are sterile, precluding incorporation into a breeding program. Hence, to transfer traits such as disease and herbicide resistance, emphasis has shifted to production of hybrids between more closely related species. Novel variation has been observed in such somatic hybrids due to segregation of mixed organelles, cytoplasmic and nuclear gene recombination, and somaclonal variation. The unique gene combinations made possible by protoplast fusion ensure that new plant varieties will soon be derived from somatic hybridization. Even though measurable success of somatic hybridization in terms of cultivar release may still be limited, the potential for their use in plant breeding remains great. In general, somatic hybridization provides excellent opportunities for research on plant improvement, first by exploring genetic variations among the existing crops and then by attempting to transfer the available genetic information from one species to another through fusion of protoplasts isolated from somatic tissues of these crops. Somatic hybridization is contributing to plant breeding in overcoming common crossing barriers among plant species. Some of the problems could be overcome by somatic hybridization are: sexual incompatibility, nucellar embryogenesis, male or female sterility, transfer of resistance genes for biotic and abiotic stresses, to create novel hybrids with increased yields. Several steps are involved in the somatic hybridization process. Some of them are: identification of the source of protoplasts, isolation of protoplasts, planting of protoplasts, regeneration of plants, fusion of protoplasts, selection procedures, identification and characterization of somatic hybrid plants.Generally somatic hybridization is playing a key role in the production of novel interspecific and intergeneric hybrids and transfer of genes for diseases resistance, abiotic stress resistance, herbicide resistance and many other quality characters. Besides being of value for the transfer of unidentified genes, somatic hybridization is a tool for the modification and improvement of polygenic traits. Furthermore, the modification of organellar genetic material is possible via somatic hybridization since a mixture of the two fusion partners is obtained in the hybrid cell Production of hybrid plants through the fusion of protoplasts of two different plant species/varieties.
\end{abstract}

Keywords: Somatic; Hybridization; Protoplast; Fusion.

\section{INTRODUCTION}

Development of hybrid plants through the fusion of somatic protoplasts of two different plant species or varieties is called somatic hybridization(Feher and Dudits, 1994). Hybrids have been produced either between different varieties of the same species (e.g. between non-flowering potato plants and flowering potato plants) or between two different species (e.g. between wheat Triticum and rye Secale to produce Triticale (Helgeson JP and Austin S, 1986). Protoplast fusion is a type of genetic modification in plants by which two distinct species of plants are fused together to form a new hybrid plant with the characteristics of both a somatic hybrid (Sink, K. C and Jain, R. K, 1992). Somatic hybridization refers to somatic cell fusion or the fusion of plant protoplasts from somatic cells of different species and the subsequent regeneration of hybrid plants from the fused protoplasts 
(Hoffmann et al., 1995). Somatic hybridization via protoplast fusion resulted in the development of both symmetric and asymmetric hybrids. Symmetric hybrid is a combination of diploid nuclear genomes and two maternal cytoplasmic genomes, whereasan asymmetric hybrid arises due to a combination of genomes of the parents or combination of the genome of one parent and the cytoplasm of another.

Somatic hybrids may express desirable and undesirable traits from the fusion parents, resulting to unpredictable phenotypes performance and thus may not be of direct use, since such hybrids contain the genome of both parents (Xu et al., 2007). Somatic hybridization is one of the most important uses of protoplast culture. This is particularly significant for hybridization between species or genera, which cannot be made to cross by conventional method of sexual hybridization (Schenk and Hildebrandt, 1969). Somatic hybridization was successfully achieved first in animals and only later in plants and its significance has been realized fully in plants because the hybrid cells can be induced to regenerate into whole plants (Evans and Bravo, 1983).

Morrison\& Bravo (1988) have recommended that production of novel hybrids through protoplast fusion should focus on four areas: (1) agriculturally important traits; (2) achieving combinations that can only be accomplished by protoplast fusion; (3) somatic hybrids integrated into a conventional breeding programme; and (4) the extension of protoplast regeneration to a wider range of crop species. Several steps are involved in the somatic hybridization process such as the source of protoplasts, the isolation of protoplasts, plating of protoplasts, regeneration of plants, fusion of protoplasts, selection procedures, and identification and characterization of the somatic hybrid plants. Protoplasts can be isolated from almost every plant species and cultured to produce callus. Protoplasts of two different species may be fused with the help of polyethylene glycol. The efficiency of protoplast fusion has been subsequently improved by the use of polyethylene glycol or high calcium $\mathrm{p}^{\mathrm{H}}$ solution or by electrical stimulation as the fusion-inducing agents.

Regardless of the technique used, protoplast fusion has proven successful for the interspecific and intergeneric transfer of genes, organelles, nuclei, or all three. Of particular benefit to plant breeders are the unique combinations of organellar (plastid, mitochondrial) and nuclear genomes that may result from protoplast fusion. This has been used to replace defective chloroplasts present in certain alloplasmic lines of cytoplasmic male sterility (RalfReski, 1994). In addition, it has been clearly demonstrated that after somatic hybridization, plant mitochondrial genomes may undergo extensive inter and intermolecular recombination, thereby creating novel mitochondrial genomes. Mitochondrial recombination after protoplast fusion was exploited for the isolation and characterization of mitochondrial sequences associated with cytoplasmic male sterility and for the transformation of mitochondria with mitochondrial DNA plasmids(Murlidhar R.V and Panda T, 2000). Nuclear genes are often the primary concern of researchers using protoplast fusion for gene transfer. It has been demonstrated that resistance gene(s) to certain pathogens, pests and the genes involved in certain secondary metabolite pathways have been transferred between species by protoplast fusion. The methods of hybrid cell selection and plant regeneration from isolated protoplasts must be empirically determined for each species. The plant cells can originate from one species in different breeding lines.In eukaryotes the transfer of genetic material form one individual to another is conventionally achieved through sexual breeding. In plants, where fairly distant species could be crossed, it has not always been possible to obtain full hybrids between desired individuals because of sexual incompatibility barriers. Protoplast fusion may be used to produce interspecific or even intergeneric hybrids. Protoplast fusion becomes an important tool of gene manipulation because it breakdown the barriers to genetic exchange imposed by conventional mating systems.

Protoplast fusion technique has a great potential for genetic analysis and for genetic improvement. It is particularly useful for industrially useful microorganisms (Murlidhar R.V and Panda T, 2000). It is now possible to regenerate plants from protoplasts of a wide range of species. As a result, genetic manipulation by protoplast fusion in vitro is now a realistic proposition. This area is exciting because protoplasts from different origins can be fused together to form new genome combinations that cannot be obtained by conventional means. Thus, protoplast fusion can be used to introduce novel germplasm into breeding programs. Somatic hybridization has been widely exploited in different horticultural crops to create novel hybrids with increased yield and resistance to diseases. In addition, somatic hybridization has also been used for salt tolerance, quality improvement, transfer of cytoplasmic male sterility (CMS), seedless triploids and rootstock improvement (Wang et al., 2013). 
A number of successful results of somatic hybridization have been achieved in members of model horticultural families. Somatic hybridization contributions to plant breeding in overcoming common crossing barriers among plant species and in organelle genetics and breeding (Evans, 1983). Benefits of the somatic hybridization are accelerated breeding and optimization without genetic engineering.Conventional breeding methods like sexual hybridization cannot transfer some elite breeding traits (quality traits, disease resistance, rapid growth rate, drought resistance, herbicide resistance, heat and cold resistance, nitrogen fixation, salt tolerance) because sexual reproductive barriers (cytoplasmic male sterility, sexual incompatibility, nuclear embryogenesis, polyembrony, different bloom phases) (Wang et al., 2013). Sexual barriers can be overcome through protoplast fusion or somatic hybridization, which is the fusion of protoplasts from two distinct species to form new hybrid plant possessing characteristics of both the parents (Carlson et al., 1972).

The technique of somatic hybridization could facilitate conventional breeding by providing novel lines so as to use them as elite breeding materials in conventional crosses for both scion and rootstock improvement. The ability to regenerate fertile plants from protoplasts of a large number of species has also led to extensive experimental work on gene transfer techniques using protoplasts. One of the earliest methods of plant gene transfer using invitro techniques was the interspecific hybridization of Nicotiana langsdorfii and N. Glauca by protoplast fusion. Further, somatic hybridization can overcome those problems associated with sexual hybridization, viz., sexual incompatibility, nucellar embryogenesis, and male or female sterility. Successful exploitation of somatic hybridization in horticultural crops mainly comes from the transfer of resistance genes for biotic and abiotic stresses from related species in several horticultural crops.

Protoplast fusion and somatic hybridization techniques allow us to move from traditional plant breeding to asexual approaches. It provides opportunity bypassing the conventional breeding barriers through direct transfer of cytoplasmic and nuclear genome to plant cells. As compared to transgenic approaches, somatic hybridization is able to broaden the germplasm base, allow the transfer of uncloned multiple genes and also able to generate products that are beyond the same legal regulations as transgene plants (Grosser and Gmitter, 2005). Further, it allows transfer of both mono- and polygenic traits (Thieme et al., 2010). In the last few years, somatic hybridization has been frequently used as an alternative for incompatible sexual crossing. As chromosome rearrangements are more typically observed in somatic hybrids than in their sexual counterparts though polyploidization and other genomic effects occurring frequently (Chevre et al., 1994). The molecular marker system would allow better tools to detect and follow the introgression of alien DNA in the receptor genome, helps in more detailed studies on genome stability and gives a better insight on genetic backgrounds that are responsible for hybrid selection during the somatic hybridization process.

Unlike transgenic technology, somatic hybridization is not affected by legal formalities and able to transfer uncloned multiple genes. However, certain boundaries and limitations of somatic hybridization restricts its use over sexual hybridization, but envisage of new genomic technologies providing better insight into the plant genomes will increase the potentiality of somatic hybridization in the betterment of agriculture. Somatic hybridization viaprotoplast fusion is an important tool for the production of interspecific and intergeneric hybrids. The technique of somatic hybridization involves the fusing protoplasts of two different genomes followed by the selection of desired somatic hybrid cells and subsequent regeneration of hybrid plant. The technique provides an efficient mean of gene transfer from one species to another so as to break the crossing barriers and integration of parental nuclear and cytoplasmic genomes (Chuong et al., 1988).

Protoplast fusion offers opportunities for circumventing barriers to sexual reproduction and gene transfer of nuclear and cytoplasmic genomes to enrich the gene pool of cultivated species.Moreover, protoplast fusion effectively generates novel germplasm for elite breeding of conventional crosses and promotes crop improvement in existing cultivars. Therefore, somatic hybridization provides excellent opportunities for research on plant improvement, first by exploring genetic variations among the existing crops and then by attempting to transfer the available genetic information from one species to another through fusion of protoplasts isolated from somatic tissues of these crops(Chuong et al., 1988). Somatic hybridization is performed by protoplast fusion and thereby cells of crop plants fuse with other cells of the same species. The main goal of somatic hybridization is to transfer properties which are desired by breeders and to generate a beneficial crop plant without genetic engineering. The 
objective/s of the paper was to review somatic hybridization and its role in crop genetic improvement through the development of hybrids without gamete fusion.

\section{Protoplast Fusionand its BiotechnOlogical APPLiCATIONSON Plants}

Protoplasts are the cells without cell walls, which cell walls are removed by lytic enzyme and cytoplasmic membrane is the outermost layer in such cells. Protoplast can be obtained by specific lytic enzymes to remove Cell wall. Protoplast fusion is a physical phenomenon, during fusion two or more protoplasts come in contact and adhere with one another either spontaneously or in presence of fusion inducing agents. By protoplast fusion, it is possible to transfer some useful genes such as disease resistance, nitrogen fixation, rapid growth rate, more product formation rate, protein quality, frost hardiness, drought resistance, herbicide resistance, heat and cold resistance from one species to another. Protoplast fusion an important tools in genotypic improvement for bringing genetic recombination and developing hybrid genotypes. Protoplast fusion has been used to combine genes from different organisms to create genotypes with desired properties. These are the powerful techniques for engineering of microbial strains for desirable industrial properties. Protoplast fusion would continue to be an existing area of research in modern biotechnology (Lucy, 1978)

This technique in the future will be one of the most frequently used research tools for tissue culturists, molecular biologists, biochemical engineers and biotechnologists. This review describes the protoplast fusion technology and its biotechnological applications. Protoplast fusion technique has a great potential for genetic analysis and for genetic improvement. It is particularly useful for industrially useful microorganisms (Murlidhar R.V And Panda T, 2000).Somatic hybridization involves many different techniques to combine genes from different organisms in order to create the desired traits and the necessary techniques start from protoplast isolation, fusion of the protoplast of the desired varieties, identification and selection of somatic hybrid cells, culture of the hybrid cells and regeneration of hybrid plants. Hybridization of somatic cells has been suggested as a possible technique to overcome the cross-incompatibility of unrelated plant species. Somatic hybrids might be of great value for crop improvement (Schenk and Hildebrandt, 1969). Hybridization of somatic plant cells requires the following steps: Removal of the cell walls to form protoplasts, Induction of close membrane contact at the molecular level and reversible membrane breakdown for fusion between two independent protoplasts (Zimmermann and Vienken, 1982), identification and selection of the somatic hybrids, Culture of the hybrid protoplasts, regeneration of plants from the hybrids.

\subsection{Source of Protoplasts}

a.Leaves: The leaf is the most convenient and popular source of plant protoplast because it allows isolation of a large number of relatively uniform cells. Protoplasts isolation from leaves involve five basic stages: a) Sterilization of leaves, b) removal of epidermal cell layer c) Pre-enzyme treatment d) incubation in enzyme and e) isolation by filtration and centrifugation. In case of monocots, leaf material is cut into small places $\left(1 \mathrm{~mm}^{2}\right)$ and then combined with vacuum infiltration. This procedure allows adequate infiltration of enzymes into leaf cells. As soon as the vacuum is removed the leaf piece will sink and eventually release the mesophyll protoplasts.

b.Callus Culture:Young actively growing callus is sub cultured and used after two weeks for protoplasts isolation.

c. Cell Suspension Culture:A high density cell suspension is centrifuged. After removing the supernant, cell are incubated in enzyme mixture (cellulose + pectinase) in a culture flask placed on a platform shaker for $6 \mathrm{hrs}$ to overnight depending on to the concentration of enzymes. A lower concentration of enzymes helps to prevent the formation of aggregates in the cell suspension in order to obtain better yield.

\section{d. Preconditioned Plant Materials:}

Mesophyll protoplasts of some crop plants have a low morphogenetic response. This is because of the fact that the physiological states of growth of a donor plant under natural condition largely affect the regeneration potential of protoplasts in this system. On the contrary, tissue cultured regenerated plants are maintained under uniform physiological conditions and therefore provides materials preconditioned for protoplasts isolation, and regeneration. This approach is particularly essential for regeneration of potato protoplasts. 


\subsection{Protoplast Isolation}

Proplast isolation is the separation of protoplast from the plant tissues for further varieties improvement through combining of varieties of the same or different species. Mechanical or enzymatic isolation are the most common approaches to remove the cell wall without damaging the protoplast.

\subsubsection{Mechanical Method}

Mechanical method of protoplast isolation was first done by Klercker since 1892. Klercker was the first to isolate protoplasts from plasmolyzed cells of Stratiotes aloides by microsurgery on plasmolyzed cells by mechanical method; however, the yields were extremely low and this method is not useful. During the mechanical protoplast fusion, the cells were kept in a suitable medium plasmolyticum and cut with a fine knife. In this process some of the plasmolyzed cells were cut only through the cell wall, releasing intact protoplasts. The mechanical methods of protoplast isolation begins with plant tissues identification, cells plasmolysis, microscope observation of cells, cutting cell wall with knife, release of protoplasm and collection of protoplasm which is ready for fusion. Mechanical method of isolation is not preferable as compared to other methods because of heavy damages of many tissues during release of intact protoplast, the yields protoplasm's are extremely low, laborious and tedious process and low protoplasm viability.

\subsubsection{Enzymatic Method}

In 1960, Cocking demonstrated the feasibility of enzymatic degradation of plant cell walls to obtain large quantities of viable protoplasts. Cocking used a concentrated solution of cellulase enzyme, prepared from cultures of the fungus, Myrothecium verrucaria, to degrade the cell walls. However, real progress in this area was made after 1968 when cellulase and macerozyme enzymes became commercially available. The commercial preparations of the enzymes for protoplast isolation were first employed by Takebe et al. (1973). The tobacco leaf species were first exposed to macerozyme to liberate single cells which were then treated with cellulase to digest the cell walls and release the protoplasts. Later, these two enzymes were used together and this is found as faster method and also reduces the chances of microbial contamination by cutting down a few steps. Enzymatic method is the most suitable isolation method that used for variety of tissues and organs and it is preferred to get high yield of protoplasts and more viable protoplasts.

\subsubsection{Enzymes Used for Breaking of Cell Walls}

For protoplast fusion, it is important that the cell wall of plant and microorganisms is degraded. So, various enzymes used for this process. Cellulose and pectinase or macerozymeacting on plant cell wall. Bacterial cell walls are degraded by the action of lysozyme. Fungalwall degraded by novozyme234 which includes glucoses and chitinase. Streptomycescellwall degraded by action of lysozyme and achromopeptidase (Jogdand, 2004).

Table1. Various Commercially Available Enzymes Commonly Used for the Isolation of Protoplast

\begin{tabular}{|l|l|l|}
\hline No & Enzyme & Source organism \\
\hline 1 & Zymolyase & Arthrobacter luteus \\
\hline 2 & Cellulose onozuka & Trichoderma viride \\
\hline 3 & Rhozyme & Aspergillus niger \\
\hline 4 & Macrozyme & Rhizopus arrhizus \\
\hline 5 & Hemicellulase & Aspergillus niger \\
\hline 6 & Macerase & Rhizopus arrhizus \\
\hline 7 & Helicase & Helix pomatia \\
\hline 8 & Pectolyase & Aspergillus japonica \\
\hline 9 & Drisclease & Irpex lacteus \\
\hline 10 & Cellulysin & Trichoderma viride \\
\hline
\end{tabular}

Source: Modern Applications of Plant Biotechnology in Pharmaceutical Sciences, (Bhatia,2015)

\subsection{Protoplast Fusion}

Protoplast fusion is a novel tool for transferring genes for a desired quality and quantity of production. In this technology, two different genetically originated protoplasts from different somatic cells are fused in order to obtain parasexual hybrid protoplasts. Genes representing useful characteristics such 
as higher bio product productivity, improved protein quality, heat and cold resistance can be transferred from one species to another.Protoplast fusion can be induced using chemical or electrical methods. In both cases, the plasmamembranes are disrupted temporarily, resulting in the formation of pores and cytoplasmic connections between adjacent protoplasts. These connections are known to inhibit pore closing and enable lipid molecules randomly oriented in the pores to unite and form membranes between adjacent protoplast (Pelletier et al., 1977). Protoplast fusion, in which living cells with cell walls removed are fused to form new living entities, has also been used successfully to overcome pre- and post-fertilization barriers.

Protoplast fusions between Brassica and Arabidopsis were reported to yield stable genotypes that incorporated chromosomes or fragments from each species (Hoffman and Adachi, 1981). Gene exchange was also reported in intergeneric somatic hybrids from protoplast fusion between B. napus and Diplotaxis harra (Klimaszewska and Keller, 1988) as well as between Sinapis turgida Del. and Brassica (Toriyama et al., 1987).Protoplast fusion is also the only means of combining two cytoplasmically inherited characteristics in a single genotype. In addition, fusion can result in a reassortment of nuclear and cytoplasmic elements. Thus, it is possible in B. napus to combine in one cell the nucleus of one parent with foreign chloroplasts and mitochondria genomes, or a mixed foreign and domestic chloroplast- mitochondrion combination, or a choice of chloroplast- genomes with a recombined mitochondrialgenome. For example, CMS B. napus plants, containing $\operatorname{radish}(R$. sativus)cytoplasm, exhibited chlorosis, especially at low temperatures, and contained low chlorophyll levels at high temperatures (Toriyama et al., 1987).

In addition, these plants had poorly developed nectaries and reduced nectar flow (Hoffman and Adachi, 1981). The chloroplast problem was solved through protoplast fusion by replacing the radish chloroplast genome with $B$. napus chloroplasts but retaining the radish mitochondria controlling the CMS trait (Pelletier et al., 1983). In the resulting hybrids variability of flower morphology was also observed, with some plants having their nectar production restored to $81 \%$ of the male fertile control. These observations indicate that a recombination of the mitochondrial genome resulted in a restoration of nectaries while retaining the male sterility trait (Pelletier, 1990).In B. napus plants, protoplast fusion and plant regeneration have also made possible the combination of the $B$. rapa chloroplasts that impart tolerance to the triazine family of herbicides with the mitochondria that control male sterility in the Ogura (Pelletier et al., 1983; Kao et al., 1992), and nap (Yarrow et al, 1986) CMS systems. Thus two cytoplasmically inherited characteristics were combined in a single genotype.

\subsection{Mechanisms of Protoplast Fusion}

Protoplast fusion is the fusion of protoplast of two different genome.The mechanism of protoplast fusion is not fully known. Several explanations have been put forward to understand the mechanism of protoplast fusion. Some are explained here: When the protoplasts are brought into close proximity, this is followed an induction phase thereby changes induced in electrostatic potential of the membrane results in fusion. After the fusion, the membrane stabilizes and the surface potential returns to their former state. Other literature showed when the protoplasts are closely adhered, the external fusogens cause disturbance in the intramembranous proteins and glycoproteins. This increases membrane fluidity and creates a region where lipid molecule intermix, allowing coalescence of adjacent membranes. The negative charge carried by protoplast is mainly due to intramembranous phosphate groups (Narayanswamy S, 1994). The addition of $\mathrm{Ca}^{2+}$ ions causes reduction in the potential of plasma membrane and under this situation protoplasts are fused(Peberdy J.F, 1980). The high molecular weight polymer (1000-6000) of polyethylene glycol acts as a molecular bridge connecting the protoplasts. Calcium ions linked the negatively charged polyethylene glycol and membrane surface.

On elution of the polyethylene glycol, the surface potential are disturbed, leading to intramembrane contact and subsequent fusion, Besides this ,the strong affinity of polyethylene glycol for water may cause local dehydration of the membrane and increase fluidity, thus inducing fusion. Protoplast fusion takes place when the molecular distance between the protoplasts is $10 \mathrm{~A}$ or less. This indicates that protoplast fusion is highly a traumatic event (Peberdy J.F, 1980).Protoplast fusion has often been suggested as a means of developing unique hybrid plants which cannot be produced by conventional sexual hybridization. Protoplasts can be produced from many plants, including most crop species. However, while any two plant protoplasts can be fused by chemical or physical means, production of 
unique somatic hybrid plants is limited by the ability to regenerate the fused product and sterility in the interspecific hybrids rather than the production of protoplasts. Perhaps the best example of the use of protoplasts to improve crop production is that of Nicotiana, where the somatic hybrid products of a chemical fusion of protoplasts have been used to modify the alkaloid and disease-resistant traits of commercial tobacco cultivars (Torrence, 2011). Protoplast fusion can be broadly classified into two categories.

Table2. Examples of Somatic Hybridization in Different Plants

\begin{tabular}{|l|l|l|l|}
\hline No & Genus & Parent species and their chromosome number & $\begin{array}{l}\text { Chromosome } \\
\text { number of hybrid }\end{array}$ \\
\hline 1 & Interspecific hybrids & & \\
\hline & Brassica & B. oleracea $(2 \mathrm{n}=18)+$ B. campestris $(2 \mathrm{n}=20)$ & Wide variation \\
\hline & & B. napus $(2 \mathrm{n}=38)+$ B. oleracea $(2 \mathrm{n}=18)$ & Wide variation \\
\hline & & B. napus $(2 \mathrm{n}=38)+$ B. nigra $(2 \mathrm{n}=16)$ & Wide variation \\
\hline & Nicotiana & B. napus $(2 \mathrm{n}=38)+$ B. carinata $(2 \mathrm{n}=34)$ & Wide variation \\
\hline & & N. tabacum $(2 \mathrm{n}=48)+$ N. alata $(2 \mathrm{n}=18)$ & $66-71$ \\
\hline & & N. tabacum $(2 \mathrm{n}=48)+$ N. glauca $(2 \mathrm{n}=14)$ & 72 \\
\hline & & N. tabacum $(2 \mathrm{n}=48)+$ N. rustica $(2 \mathrm{n}=48)$ & $60-91$ \\
\hline & & N.tabacum $(2 \mathrm{n}=48)+$ N. octophora $(2 \mathrm{n}=24)$ & 48 \\
\hline & & N.tabacum $(2 \mathrm{n}=48)+$ N. mesophila $(2 \mathrm{n}=48)$ & 96 \\
\hline 2 & Intergeneric hybrids & N.tabacum $(2 \mathrm{n}=48)+$ N. glutinosa $(2 \mathrm{n}=24)$ & $50-88$ \\
\hline & Raphanus $\times$ Brassica & Raphanus sativus + B. oleracea & \\
\hline & Moricandia $\times$ Brassica & Moricandia arvensis + B. oleracea & Raphanobrassica \\
\hline & Eruca $\times$ Brassica & Eruca sativa + B. napus & Moricandiobrassica \\
\hline & Nicotiana $\times$ Lycopersicon & Nicotianatabacum + Lycopersiconesculentum & Nicotiopersicon \\
\hline & Nicotiana $\times$ Petunia & Nicotiana tabacum + Petunia inflorata & Nicotiopetunia \\
\hline & Solanum $\times$ Lycopersicon & Solanumtuberosum + Lycopersiconesculentum & Solanopersicon \\
\hline & Datura $\times$ Atropa & Datura inoxia + Atropa belladonna & Daturotropa \\
\hline 3 & Intertribal hybrids & & \\
\hline & Arabidopsis $\times$ Brassica & Arabidopsis thaliana + B. campestris & Arabidobrassica \\
\hline & Thlaspi $\times$ Brassica & Thlaspi perfoliatum + B. napus & Thlaspobrassica \\
\hline
\end{tabular}

Source: Modern Applications of Plant Biotechnology in Pharmaceutical Sciences, (Bhatia, 2015)

\section{Spontaneous Fusion}

Protoplasts, during isolation, often fuse spontaneously and this phenomenon is called spontaneous fusion. Simple physical contact is sufficient to bring about the spontaneous fusion among the similar parental protoplasts. During the enzyme treatment for the isolation of protoplasts, it is found that protoplasts from adjoining cells fuse through their plasmodesmata to form a multinucleate protoplast. Electron microscopic studies have shown that as the cell walls are enzymatically degraded, the plasmodesmatal connection between the adjacent cells enlarge due to removal of its constriction and the enlargement of pit fields. Eventually, the greater enlargement of plasmodesmata allows the entry of organelles into neighboring cells. Finally a complete coalescence of adjacent cell takes place. Spontaneous fusion is strictly intraspecific and gives rise to homokaryon.

\section{Induced Fusion}

Fusion of freely isolated protoplasts from different sources with the help of fusion inducing chemical agents is known as induced fusion. Normally, isolated protoplasts do not fuse with each other because the surface of the isolated protoplast carries negative charge $(-10$ to $-30 \mathrm{mV})$ around the outside of plasma membrane and, thus, there is a strong tendency for protoplasts to repel one another due to their same charges. So this type of fusion needs a fusion inducing chemical agent or system which actually reduces the electronegativity of the isolated protoplasts and allows them to fuse with each other (Narayanswamy S, 1994). Actually, induced fusion is a highly important and a valuable technique because the protoplast from widely different and sexually incompatible plants can be fused by this procedure. This technique has the possibility and ability to combine different genotypes beyond the limits imposed by sexual process. The fundamental objectives of somatic hybridisation are mainly based on induced protoplast fusion. The isolated plant protoplasts can be induced to fuse by three ways: 


\section{Mechanical Fusion}

In this process, the isolated protoplasts are brought into intimate physical contact mechanically under microscope using micromanipulator and perfusion micropipette. This micropipette is partially blocked within $1 \mathrm{~mm}$ of the tip by a sealed glass rod. In this way the protoplasts are retained and compressed by the flow of liquid. By this technique occasional fusion of protoplast has been observed.In this process the isolated protoplast are brought into intimate physical contact mechanically under microscope using micromanipulator or perfusion micropipette.

\section{Chemo Fusion}

Several chemicals have been used to induce protoplast fusion such as sodium nitrate, polyethyleneglycol (PEG), dextran, and polyvinyl alcohol (PVA), Calcium ions.High molecular weight watersoluble polymer, polyethylene glycol (PEG), has been identified as a potent fusogen. The polymer binds with the lipid membrane of cells and thus induces fusion. The most effective chemical fusion of protoplast is obtained by combining polyethylene glycol and calcium. $\mathrm{NaNO}_{3}$ is not preferred due to low frequency of fusion, particularly when highly vacuolated mesophyll protoplasts are used.Polyethylene glycol is the chemical most commonly used for this purpose. Polyethylene glycol with a low carbonyl content, such as 30\% PEG 1500 solution, must be used to obtain a high frequency of heterokaryon formation (above 10\% of the treated protoplasts) and to ensure viability(Pasha C. R et al., 2007). The development of biotechnological tools, including protoplast fusion, provides a means of circumventing the natural barriers of the reproductive biology of various species found in conventional breeding systems. To generate the hybrids, protoplasts were isolated from embryogenic calli and leaves and were chemically fused using polyethylene glycol. The plants were regenerated via somatic embryogenesis, and somatic hybridization was confirmed through leaf morphology, cytology, and DNA (RAPD) analyses (Iwata, M et al., 2003).Chemofusion is a non-specific, inexpensive, can cause massive fusion product, can be cytotoxic and non-selective and having less fusion frequency.

\section{Electro Fusion}

Electro fusion is rapid (usually completes within $15 \mathrm{~min}$ ), simple, synchronous and more easily controlled. It was shown that electrofusion is more effective than polyethylene glycol mediated fusion in somatic hybridization of Solanum tuberosum and S. brevidens.

Zimmermann et al. (1982) developed a method, which is claimed to be 10000 times better than any other method for protoplast fusion.In electric fusion protoplasts are placed into a small culture vessel containing electrodes and a potential difference is applied, then the protoplast will line up between the electrodes. Alternate generation of AC and DC pulse are two steps required for electric fusion. This method is more reproducible and less damaging but requires expensive equipment. The following steps are used in protoplast electrofusion: (1) alternating current is used to transfer the protoplasts and to promote a close contact between the membranes, and (2) continuous short pulses are used to induce membrane disruption at the contact points (Geerts et al., 2008). Despite the need for expensive and sophisticated equipment to generate alternating current fields and continuous current pulses, the electrofusion method has become increasingly popular because it is less damaging to protoplasts than chemical procedures.

\section{Characteristics of Somatic Hybridization and Cybridization}

Somatic cell fusion appears to be the only means through which two different parental genomes can be recombined among plants that cannot reproducesexually. Protoplasts of sexually sterile (haploid, triploid, and aneuploidy) plants can be fused to produce fertile diploids and polyploid. Somatic cell fusion overcomes sexual incompatibility barriers. In some cases somatic hybrids between two incompatible plants have also found application in industry or agriculture. Somatic cell fusion is useful in the study of cytoplasmic genes and their activities and this information can be applied in plant breeding experiments.

\section{Applications of Somatic Hybridization in Crop Improvement}

Improvement of crop plants by conventional breeding is impossible because of cytoplasmic male sterility, sexual incompatibility and others sexual barriers reasons. However, Protoplast fusion and somatic hybridization have opened up a new avenue in plant science. It is now a well-known fact that the somatic hybridization in plants can be used in the improvement of plants. One of these is the 
production of hybrids which is not possible through normal sexual fusion or fertilization process (Grosser et al., 1989). Somatic hybridization is especially useful for heterozygotic crops, which possess different ploidy levels. An efficient utilization of genetic diversity present in economic plants and in their wild relatives, and the introduction of a stable resistance to diseases by somatic hybridization and/or by molecular biological techniques will lead to crops with improved traits.

Novel inter-specific and inter-generic crosses which are difficult to produce by conventional methods can be easily obtained. Important characters, such as resistance to diseases, ability to undergo abiotic stress and other quality characters can be obtained in hybrid plant by the fusion of protoplasts of plant bearing particular character to the other plant which may be susceptible to diseases. Protoplasts of sexually sterile haploid, triploid, aneuploid plants can be used to obtain fertile diploids and polyploidy (Ohgawara et al., 1988). Most of the agronomically important traits, such as cytoplasmic male sterility, antibiotic resistance and herbicide resistance, are cytoplasmically encoded, hence can be easily transferred to other plant. Plants in juvenile stage can also be hybridized by means of somatic hybridization. Somatic hybridization can be used as a method for the production of autotetraploids. Cytoplasm transfer can be done in one year, while back crossing may take 6-7 years. Even where backcrossing is not applicable, cytoplasm transfer can be made using this approach. Generally, somatic hybrids are used for transfer of useful genes such as disease resistance, abiotic stress resistance or genes of industrial use. Somatic hybridization by protoplast fusion, on the other hand, has been a powerful tool in genetic improvement (Mendes et al., 2001).

\section{Means of Genetic Recombination in Asexual or Sterile Plants}

Somatic cell fusion appears to be the only approach through which two different parental genomes can be recombined among plants that cannot reproduce sexually. Similarly, protoplast of sexually sterile plants can be fused to produce fertile diploids and polyploids. There are several reports describing the amphidiploid and hexamploid plants produced from fusion of haploid protoplasts of tobacco. Protoplasts isolated from dihaploid potato clones have been fused with isolated protoplasts of Solanum brevidens to produce hybrids of practical breeding value. Haploid protoplasts from an anther- derived callus of rice cultivars upon fusion also produce fertile diploid and triploid hybrids.

\section{Overcoming Barriers of Sexual Incompatibility}

To overcome sexual incompatibility, Production of novel interspecific and intergeneric crosses between plants that are difficult or impossible to hybridize conventionally. In plant breeding programmes, sexual crossing at Interspecific and Intergeneric levels often fails to produce hybrids due to incompatibility barriers, which can be overcome by somatic cell fusion. Melchers and Labib used albino mutants for the complementation selection of green intraspecific hybrids of tobacco. Interspecific somatic hybrid plants from sexually incompatible species have been raised in Nicotiana, Petunia, Daucus, and Datura.Schieder (1978) obtained amphidiploid Datura innoxia (+) D. discolor and D. innoxia (+) D. stramonium, by fusing their diploid mesophyll protoplast. These hybrids cannot be produced conventionally and they are industrially important because show heterosis and higher (20-25\%) scopolamine content than in the parental forms. Nicotiana repanda, N.nesophila and N.stockoni are resistant to number of disease but are not sexually crossable with N. tabacum (Tobacco).

\section{Cytoplasm Transfer}

Being naked in nature, isolated protoplasts are considered to be very suitable for genetic and cytoplasmic modifications. It has been reported that plant protoplast has a unique property in uptaking isolated nuclei, DNA, chromosomes, chloroplasts, cyanobacteria, nitrogenfixingbacteria, and virus particles.Productions of cybrids, Cybrids are cells or plants containing the nucleus of one species and cytoplasm of both parenteral species. These are generally produced during protoplast fusion in variable frequencies. Cybrid formation may result by fusion of normal protoplasts of one species with enucleated protoplasts (cytoplasm), elimination of the nucleus of one species from a normal heterokaryon, or gradual elimination of the chromosomes of one species from a hybrid cell during further mitotic division. The cybrids can be produced in high frequencies by irradiation of one parenteral protoplast before fusion in order to inactivate the nuclei or by preparing enucleate protoplasts of one species and fusing them with normal protoplasts of another species (Power et.al., 1975). 


\section{Disease and Insect Resistance}

Many disease resistance genes could be successfully transferred from one species to another. For example, resistance has been introduced in tomato against diseases such as tobacco mosaic virus, spotted wilt virus and insect pests. Asymmetric somatic hybridization was exploited for transfer of bacterial blight resistance trait from wild Oryza meyeriana L. to Oryza sativa L. ssp. Japonica (Yan et al., 2008). Asymmetric hybridization is very promising as it allows partial genome transfer (Liu \& Deng, 2002), which may be better tolerated than a whole-genome transfer (Ramulu et al., 1996). As in other agricultural species, trait introgression from wild species of the genus Nicotiana has been used to improve the cropped species, and characters from at least 13 different species have been transferred into tobacco (Lewis, 2011).

\section{Germplasm Diversification}

Somatic hybridization via protoplast fusion brings together the genomes of two species and exploited to transfer mono or polygenic traits (Liu et al., 2005). It also creates novel genotypes by combining cytoplasmic genomes of different species or cultivars. Many inter specific, inter generic, intertribal, and even interfamilial somatic hybrid plants generated through this approach. A countable number of reports are available on somatic hybrids involving grasses Somatic hybridization through protoplast fusion can be a relevant tool in genetic improvement of grasses(Xiang et al., 2010).

\section{Factors Affecting Regeneration of Hybrid Plants}

Successful gene transfer via protoplast fusion depends on the ability to regenerate a mature plant from the fusion product. Many factors affecting regeneration of plants, such as the nature of protoplast (Nassour and Dorion, 2002), culture method, culture medium (Sonntag et al., 2009), protoplast density (Khentry et al., 2006), and external conditions have been reported. Selection of parents is very important in using hybridization to create new variation. Despite the obvious importance of this issue, more research has been done on methods of selection in breeding populations than on selection of parents to create these populations

The somatic hybrids between remotely related species were, in general, more difficult to root and culture to mature plants outside in vitro conditions (Tu et al., 2008). Du et al. (2009) reported that most of the hybrids between B. napus and Isatis indigotica developed shoots and roots very slowly, and even some rooted plants failed to survive after being transferred to soil or stopped growing and died during the flowering stage, although care was taken with soil and humidity conditions. The poor performance of these hybrids may be related to the incorporation of excessive genomes of the two very distantly related species and strong genetic incompatibilities. Somatic hybrids from parents of a widely divergent genetic background may have low fertility and viability (Navratilova, 2004). Efficient protoplast isolation, fusion, and regeneration of fusion products are all indispensable steps toward the creation of a somatic hybrid and therefore demand an integrated approach of techniques (Duquenne et al., 2007; Pati et al., 2008).

\section{CONCLUSION}

Hybridization of somatic cells has been suggested as a possible technique to overcome the crossincompatibility of unrelated plant species. Somatic hybrids might be of great value for crop improvement. These advances have become possible because of the improvement in techniques for protoplast isolation, culture, fusion and selection of heterokaryocytes. Somatic hybridization is a technique which allows the manipulation of cellular genomes by protoplast fusion. Its major contribution to plant breeding is in overcoming common crossing barriers among plant species and in organelle genetics and breeding.Protoplast fusion is a type of genetic modification in plants by which two distinct species of plants are fused together to form a new hybrid plant with the characteristics of both, a somatic hybrid.

Somatic hybridization technique follows the following steps:Isolation of protoplastFusion of the protoplasts of desired species/varietiesIdentification and selection of somatic hybrid cells Culture of the hybrid cellsRegeneration of hybrid plants.Isolation of protoplast or separation of protoplasts from plant tissue can be done through mechanical and enzymatic methods.Somatic hybridization using protoplast fusion is a promising tool to produce symmetrical and asymmetrical polyploidy somatic hybrids in many agricultural crops. The technique of somatic hybridization could facilitate 
conventional breeding by providing novel lines so as to usethem as elite breeding materials in conventional crosses for both scion and rootstock improvement. Somatic hybridization via protoplast fusion is an important tool for the production of interspecific and intergeneric hybrids.

Transgenic plant production has certainly overwhelmed somatic hybridization as a technique heavily utilized by plant breeders and geneticists over the past decade. This is understandable considering that transgenic modification theoretically affects only a single trait of interest without introducing innumerable extraneous genes of uncertain agronomic influence. The opportunity of genetic revision of existing cultivars is afforded by genetic engineering. Conversely, somatic hybridization involves introgressing traits of interest into crop plants without any prior knowledge of their genetic control. Resulting somatic hybrids are generally not expected to be ready for cultivar release without additional breeding effort to acquire the trait of interest in a more acceptable genetic background resembling current cultivars. However, an advantage of somatic hybridization compared to genetic engineering concerns the controversy surrounding genetically modified organisms, a stigma that does not apply somatic hybrids. Current restrictions that hinder the release of transgenic crops are avoided using somatic hybrid plant material.

The impact of somatic hybridization can be expected to be much quieter than that of genetic engineering because traditional breeding must intervene between the biotechnological events (protoplast fusion) and the release of a product for market. Valuable resistances to various pathogens or environmental stresses have been identified in direct somatic hybrids and many have been entered into current plant breeding programs. Generally somatic hybridization is very relevant in production of novel interspecific and intergenic hybrids. Production of fertile diploids and polypoids from sexually sterile haploids, triploids and aneuploids is very crucial in advancement of crop improvement. Transfer gene for disease resistance, abiotic stress resistance, herbicide resistance and many other quality characters through integration of protoplast is increasing the fate crop improvement, even if it is not possible byconventional breeding programme.

\section{REFERENCES}

[1] Bhatia, S., Sharma, K., Dahiya, R. and Bera, T., 2015. Modern applications of plant biotechnology in pharmaceutical sciences. Academic Press.

[2] Blow, A.M.J., Botham, G.M., Fisher, D., Good all, A.H., Tilcock, C.P.S. and Lucy, J.A., 1978. Water and calcium ions in cell fusion induced by poly (ethylene glycol). FEBS letters, 94(2), pp.305-310.

[3] Bonnemann, C.G., Modi, R., Noguchi, S., Mizuno, Y., Yoshida, M., Gussoni, E., McNally, E.M., Duggan, D.J., Angelini, C., Hoffman, E.P. and Ozawa, E., 1995. B-sarcoglycan (A3b) mutations cause autosomal recessive muscular dystrophy with loss of the sarcoglycan complex. Nature genetics, 11(3), pp.266-273.

[4] Carlson, P.S., Smith, H.H. and Dearing, R.D., 1972.Parasexual interspecific plant hybridization. Proceedings of the National Academy of Sciences, 69(8), pp.2292-2294.

[5] Chevre, A.M., Eber, F., Margale, E., Kerlan, M.C., Primard, C., Vedel, F., Delseny, M. and Pelletier, G., 1994. Comparison of somatic and sexual Brassica napus-Sinapis alba hybrids and their progeny by cytogenetic studies and molecular characterization. Genome, 37(3), pp.367-374.

[6] Chuong, P.V., Beyersdorf, W.D., Powell, A.D. and Pauls, K.P., 1988. Somatic transfer of cytoplasmic traits in Brassica napus L. by haploid protoplast fusion. Molecular and General Genetics MGG, 211(2), pp.197-201.

[7] Ding, J.Q., Wang, X.M., Chander, S., Yan, J.B. and Li, J.S., 2008. QTL mapping of resistance to Fusarium ear rot using a RIL population in maize. Molecular breeding, 22(3), pp.395-403.

[8] Du, X.Z., Ge, X.H., Yao, X.C., Zhao, Z.G. and Li, Z.Y., 2009. Production and cytogenetic characterization of intertribal somatic hybrids between Brassica napus and Isatis indigotica and backcross progenies. Plant cell reports, 28(7), pp.1105-1113.

[9] Duquenne, B., Eeckhaut, T., Werbrouck, S. and Van Huylenbroeck, J., 2007. Effect of enzyme concentrations on protoplast isolation and protoplast culture of Spathiphyllum and Anthurium. Plant cell, tissue and organ culture, 91(2), pp.165-173.

[10] Evans, D.A., 1983. Agricultural applications of plant protoplast fusion. Bio/technology, 1(3), pp.253-261.

[11] Evans, D.A., Bravo, J.E., Kut, S.A. and Flick, C.E., 1983. Genetic behavior of somatic hybrids in the genus Nicotiana: N. otophora+ N. tabacum and N. sylvestris+ N. tabacum. Theoretical and Applied Genetics, 65(2), pp.93-101.

[12] Feher, A. and Dudits, D., 1994. Plant protoplasts for cell fusion and direct DNA uptake: culture and regeneration systems. In Plant cell and tissue culture (pp. 71-118). Springer, Dordrecht. 
[13] Geerts, P., Druart, P., Ochatt, S. and Baudoin, J.P., 2008. Protoplast fusion technology for somatic hybridisation in Phaseolus.

[14] Grosser, J.W. and Gmitter, F.G., 2005. 2004 SIVB Congress Symposium Proceedings "Thinking Outside the Cell": Applications of Somatic Hybridization and Cybridization in Crop Improvement, with Citrus as a Model. In Vitro Cellular \& Developmental Biology-Plant, 41(3), pp.220-225.

[15] Grosser, J.W., Moore, G.A. and Gmitter Jr, F.G., 1989. Interspecific somatic hybrid plants from the fusion of 'Key'lime (Citrus aurantifolia) with 'Valencia'sweet orange (Citrus sinensis) protoplasts. Scientia horticulturae, 39(1), pp.23-29.

[16] Helgeson, J.P., Hunt, G.J., Haberlach, G.T. and Austin, S., 1986. Somatic hybrids between Solanum brevidens and Solanum tuberosum: Expression of a late blight resistance gene and potato leaf roll resistance. Plant Cell Reports, 5(3), pp.212-214.

[17] Hoffmann, F. and Adachi, T., 1981. "Arabidobrassica": Chromosomal recombination and morphogenesis in asymmetric intergeneric hybrid cells. Planta, 153(6), pp.586-593.

[18] Kao, H.M., Keller, W.A., Gleddie, S. and Brown, G.G., 1992. Synthesis of Brassica oleracea/Brassica napus somatic hybrid plants with novel organelles DNA compositions. Theoretical and Applied Genetics, 83(3), pp.313-320.

[19] Khentry, Y., Paradornuvat, A., Tantiwiwat, S., Phansiri, S. and Thaveechai, N., 2006. Protoplast isolation and culture of Dendrobium Sonia "Bom 17". Kasetsart Journal (Natural Science), 40, pp.361-369.

[20] Klimaszewska, K. and Keller, W.A., 1988. Regeneration and characterization of somatic hybrids between Brassica napus and Diplotaxis harra. Plant Science, 58(2), pp.211-222.

[21] Laxman, R.S., More, S.V., Rele, M.V., Rao, B.S.R., Jogdand, V.V., Rao, M.B., Deshpande, V.V., Naidu, R.B., Manikandan, P., Kumar, D.A. and Kanagaraj, J., 2004. Process for the preparation of alkaline protease. U.S. Patent 6,777,219.

[22] Liu, Y., Schiff, M. and Dinesh-Kumar, S.P., 2002. Virus-induced gene silencing in tomato. The Plant Journal, 31(6), pp.777-786.

[23] Liu, Y.G., Chen, S.L., Li, B.F., Wang, Z.J. and Liu, Z., 2005. Analysis of genetic variation in selected stocks of hatchery flounder, Paralichthys olivaceus, using AFLP markers. Biochemical systematics and ecology, 33(10), pp.993-1005.

[24] Mendes, B.M., Francisco de Assis Filho, A.M., Farias, P.C.D.M. and Benedito, V.A., 2001. Citrus somatic hybridization with potential for improved blight and CTV resistance. In Vitro Cellular \& Developmental Biology-Plant, 37(4), pp.490-495.

[25] Moon, J., Skibbe, D., Timofejeva, L., Wang, C.J.R., Kelliher, T., Kremling, K., Walbot, V. and Cande, W.Z., 2013. Regulation of cell divisions and differentiation by male sterility 32 is required for anther development in maize. The Plant Journal, 76(4), pp.592-602.

[26] Morrison, R.A. and Evans, D.A., 1988. Haploid plants from tissue culture: new plant varieties in a shortened time frame. Bio/technology, 6(6), pp.684-690.

[27] Muralidhar, R.V. and Panda, T., 2000. Monoclonal antibodies specific against tumors and viral infections. Bioprocess Engineering, 22(5), pp.421-427.

[28] Narayanswamy, S., 1994. Plant protoplast: isolation, culture and fusion. Plant cells and tissue cultures. TATA MCGraw Hill Publishing, New Delhi.

[29] Nassour, M. and Dorion, N., 2002. Plant regeneration from protoplasts of micropropagated Pelargonium x hortorum 'Alain': effect of some environmental and medium factors on protoplast system efficiency. Plant science, 163(1), pp.169-176.

[30] Navratilova, B., 2004. Protoplast cultures and protoplast fusion focused on Brassicacea review. Hort Sci (Prague), 31(4), pp.140-157.

[31] \Oeda, K., Sakaki, T., Ohkawa, H., Yabusaki, Y., Murakami, H., Nakamura, K. and Shimizu, M., Agency of Industrial Science, 1988. Cytochrome P-450MC gene, expression plasmid carrying the said gene, yeasts transformed with the said plasmid and a process for producing cytochrome P-450MC by culturing the said transformant yeasts. U.S. Patent 4,766,068.

[32] Pasha, C., Kuhad, R.C. and Rao, L.V., 2007. Strain improvement of thermotolerant Saccharomyces cerevisiae VS3 strain for better utilization of lignocellulosic substrates. Journal of applied microbiology, 103(5), pp.1480-1489.

[33] Pati, P.K., Sharma, M. and Ahuja, P.S., 2008. Rose protoplast isolation and culture and heterokaryon selection by immobilization in extra thin alginate film. Protoplasma, 233(1-2), pp.165-171.

[34] Peberdy, J.F., 1980. Protoplast fusion a tool for genetic manipulation and breeding in industrial microorganisms. Enzyme and Microbial Technology, 2(1), pp.23-29. 
[35] Pelletier, G., 1990. Cybrids in oilseed Brassica crops through protoplast fusion. In Legumes and Oilseed Crops I (pp. 418-433).

[36] Pelletier, G., Primard, C., Vedel, F., Chetrit, P., Remy, R. and Renard, M., 1983. Intergeneric cytoplasmic hybridization in Cruciferae by protoplast fusion. Molecular and General Genetics MGG, 191(2), pp.244250.

[37] Power, J.B., Frearson, E.M., Hayward, C. and Cocking, E.C., 1975. Some consequences of the fusion and selective culture of Petunia and Parthenocissus protoplasts. Plant Science Letters, 5(3), pp.197-207.

[38] Ramulu, K.S., Dijkhuis, P., Rutgers, E., Blaas, J., Krens, F.A., Verbeek, W.H.J., Colijn-Hooymans, C.M. and Verhoeven, H.A., 1996. Intergeneric transfer of a partial genome and direct production of monosomic addition plants by microprotoplast fusion. Theoretical and Applied Genetics, 92(3-4), pp.316-325.

[39] Reski, R., Faust, M., Wang, X.H., Wehe, M. and Abel, W.O., 1994. Genome analysis of the moss Physcomitrella patens (Hedw.) BSG. Molecular and General Genetics MGG, 244(4), pp.352-359.

[40] Sink, K.C., Jain, R.K. and Chowdhury, J.B., 1992. Somatic cell hybridization. In Distant Hybridization of Crop Plants (pp. 168-198).

[41] Takebe, I., Otsuki, Y., Honda, Y., Nishio, T. and Matsui, C., 1973. Fine structure of isolated mesophyll protoplasts of tobacco. Planta, 113(1), pp.21-27.

[42] Tani, N., Takahashi, T., Iwata, H., Mukai, Y., Ujino-Ihara, T., Matsumoto, A., Yoshimura, K., Yoshimaru, H., Murai, M., Nagasaka, K. and Tsumura, Y., 2003. A consensus linkage map for sugi (Cryptomeria japonica) from two pedigrees based on microsatellites and expressed sequence tags. Genetics, 165(3), pp.1551-1568.

[43] Thieme, R., Rakosy-Tican, E., Nachtigall, M., Schubert, J., Hammann, T., Antonova, O., Gavrilenko, T., Heimbach, U. and Thieme, T., 2010. Characterization of the multiple resistance traits of somatic hybrids between Solanum cardiophyllum Lindl and two commercial potato cultivars. Plant cell reports, 29(10), pp.1187-1201.

[44] Toriyama, K., Hinata, K. and Kameya, T., 1987. Production of somatic hybrid plants, 'Brassicomoricandia', through protoplast fusion between Moricandia arvensis and Brassica oleracea. Plant Science, 48(2), pp.123-128.

[45] Torrance, L., 2001. Virus Diseases of Potatoes. eLS, pp.1-7.

[46] Tu, Y., Sun, J., Liu, Y., Ge, X., Zhao, Z., Yao, X. and Li, Z., 2008. Production and characterization of intertribal somatic hybrids of Raphanus sativus and Brassica rapa with dye and medicinal plant Isatis indigotica. Plant cell reports, 27(5), pp.873-883.

[47] Vales, T., Feng, X., Ge, L., Xu, N., Cairney, J., Pullman, G.S. and Peter, G.F., 2007. Improved somatic embryo maturation in loblolly pine by monitoring ABA-responsive gene expression. Plant cell reports, 26(2), pp.133-143.Shenk, R.U. and Hildebrandt, A.C., 1969. Production of Protoplasts from Plant Cells in Liquid Culture Using Purified Commercial Cellulases 1. Crop Science, 9(5), pp.629-631.

[48] Wellner, U., Schubert, J., Burk, U.C., Schmalhofer, O., Zhu, F., Sonntag, A., Waldvogel, B., Vannier, C., Darling, D., Zur Hausen, A. and Brunton, V.G., 2009. The EMT-activator ZEB1 promotes tumorigenicity by repressing stemness-inhibiting microRNAs. Nature cell biology, 11(12), pp.1487-1495.

[49] Yarrow, S.A., Wu, S.C., Barsby, T.L., Kemble, R.J. and Shepard, J.F., 1986. The introduction of CMS mitochondria to triazine tolerant Brassica napus L., var. "Regent", by micromanipulation of individual heterokaryons. Plant Cell Reports, 5(6), pp.415-418.

[50] Zhao, Q.P., Jiang, M.S., Littlewoods, D.T.J. and Nie, P., 2010. Distinct genetic diversity of Oncomelania hupensis, intermediate host of Schistosoma japonicum in mainland China as revealed by ITS sequences. PLoS neglected tropical diseases, 4(3).

[51] Zimmermann, U. and Vienken, J., 1982. Electric field-induced cell-to-cell fusion. The Journal of membrane biology, 67(1), pp.165-182.

Citation: Temesgen Begna (2020). "Review on Somatic Hybridization and its Role in Crop Improvement". ", International Journal of Research Studies in Agricultural Sciences (IJRSAS), 6(6), pp. 25-37. DOI: http://dx.doi.org/10.20431/2454-6224.0606004

Copyright: (C) 2020Authors. This is an open-access article distributed under the terms of the Creative Commons Attribution License, which permits unrestricted use, distribution, and reproduction in any medium, provided the original author and source are credited. 